\title{
Research on the Influence of Group Dynamics Mechanism on Individual Performance in ESL System
}

\author{
WENG Yifei \\ (North China Institute of Science and Technology, Beijing, P.R. China 101601) \\ yifeiweng@126.com
}

\begin{abstract}
Keywords: ESL; group dynamics; individual performance; psychological and behavioral analysis; statistical analysis
\end{abstract}

\begin{abstract}
In this thesis, group dynamics mechanism in ESL teaching and learning system is researched. First of all connotations and significance of ESL are introduced. And then group dynamics mechanism of ESL system is qualitatively analyzed from the views of system, psychology and behavior, with main viewpoints that to stimulate and keep students' interest continuously in learning English, group dynamics can make a effective field to influence and revise members' psychology and behavior positively to improve the English level individually and totally; driven by group dynamics, members and groups' average English level and performance are enhanced and convergent. Finally quantitatively analysis is made to demonstrate the benign effect of group dynamics and the gap among the members and groups becoming closer.
\end{abstract}

\section{Introduction}

It is well known for us that arousing and keeping students' interest in English is important and difficult in ESL teaching. After the novelty at the very beginning, together with pressure of exam, students may feel inadequate and bored at the words, phrases, sentences, paragraphs and essays under a self and passive learning mode. Actually language itself, as a tool of communication, coming and developing from communication, needs environment of communication. Utilization of group learning and group dynamics in ESL teaching can just cater such needs. So the topic of this thesis is the application of group dynamics theory on ESL teaching, especially on the psychological and behavioral rules and tracks and performance of individual students, group and instructors under ESL educational framework.

\section{Connotations and Significance of ESL}

English as a Second language (ESL) is a non-mother-tone educational system of English. In broad sense, all kinds of English education for the people with other mother tone can be called ESL; and in narrow sense, it is a scientific system including special education of listening, speaking, reading, vocabulary, grammar, writing, etc., in order to improve the comprehensive practical ability of using English to learn, research, live and communicate. ESL in this thesis refers to the narrow sense. In this thesis, an international joint program of business administration in North China Institute of Science and Technology (NCIST) will be researched as an example since ESL in this program is organized as a completed system. In America and Europe, ESL is more popular for new immigrants, international students and scholars.

\section{Psychological and Behavioral Analyses under ESL Education Framework}

\subsection{Process of Establishing Group Learning of ESL}

1) Forming. According to the placement test or performance appraisal last semester, students will have a new class in a certain ESL level, most in an upper level, as well as a few repeaters in an old level but a new class. In a new class, students will be divided into different groups or work teams by instructors or themselves spontaneously. 
2) Performing. After reorganizing and forming, different classes, groups will perform their functions. As we know, the first relationship is instructor-students, and group can be recognized the second one. In the first relationship, students can learn knowledge and skills of a certain ESL level from instructors. In the second relationship, students can improve their English level through cooperative learning, interactive learning, and sharing others' knowledge and ideas of learning English. Specifically, students can learn, discuss, communicate, prepare for the presentations, speak together and help each other in the group dynamics framework. Group dynamics is to guide and arouse individuals to be different with and more active than alone, then produce the synergic effect of " $1+1>2$ ".

3) Controlling. Through a period of interaction, the functions of group may change into unexpected directions and goals because all kinds of communication among members may not focus on learning English but other entertainment like computer games, movies, sports, thus the instructor has to control, adjust and correct the deviations to guarantee the groups in right track. The countermeasures include breaking and reorganizing the group, communicating with the members to regulate their behaviors in the group, etc.

4) Ending. When a semester ends, many groups will be broken and ended; even if the members keep the same in the next semester, the goal and psychological and behavioral rules will change more or less because of the change of ESL level.

3.2 Functioning Mechanism of Group Dynamics

In the framework of group dynamics mechanism, as long as there are others on the spot together with you, your psychology and behavior will be influenced by others and different with alone. So an individual student will be different in an ESL group, compared with his or her learning English alone. With correct guidance and the formation of competitive and cooperative environment, students in a pertinent ESL group will influence, promote and encourage each other.

There are some types of relationship in ESL group. 1) Instructor-group relationship: an instructor has the right to regulate, influence, guide and control all the groups in his or her class, in order to realize the teaching goal of enhancing students' English level; and groups must obey the instructor's management. 2) Inner-group relationship: members in the same group are interactive, so it is expected that all the members' English level is enhanced through group dynamics; meanwhile a group must maintain the correct goals and interests of its members, and make nobody left behind in learning English. 3) Inter-group relationship: this is an either cooperative or competitive relationship, and inter-group communication and interaction are similar to the interpersonal relationship in a group. Obviously each group's English level obtaining more progress can make the whole class better.

\subsection{Field Theory, Individual Motive and Realization Driven by ESL Group Dynamics}

A group of learning ESL can be treated as a field. Elements within this field will influence each other to make their attributes convergent. Specifically, strong (good) points in the field can make weak (bad) points stronger (better), conversely weak (bad) ones can make strong (good) ones weaker (worse). If we need a strong or good result, strong or good points should be stressed and activated, with weak or bad points' influences decreased and pressed pertinently. In ESL group, a student with good English level is a good point, which has the effect of diffusion, so the instructor and group have to utilize this to help others to improve their English. In the language of system science, assimilation makes the entropy of the ESL group system decrease. Herein good and bad are relative, as well as strong and weak. We can describe the track of individual psychology and behavior driven by group dynamics mechanism. At the very beginning, a student has the will to learn English well, but not good at expressing himself especially in public. And then, after placement test, he is arranged into an ESL level 04 class with 30 students, and into a group spontaneously with 5 students. With the running of learning, he finds that group work is required everywhere, homework, writing, presentation, discussion, dialogue, forcing him to open his mind, change his shyness, actively communicate with other partners. Meanwhile he also finds that some partners' English is better than his, and can learn more knowledge and skills of speaking, writing, etc. from them. In other word, he feels in a field, actively and passively motivated to learn. 
Gradually he is more interested in learning English. Finally his English ability and grade of exam are increased, as well as his partners' scores and abilities are improved and close.

\section{Statistical Analysis of individual and Group Performance}

\subsection{Observed Subjects and Sample Selection}

To prove the benign effect of group dynamics in ESL teaching and learning system, mainly including the increase of average English level and the decrease of deviation within a group even a class, the students' grades of ESL in different levels are selected as the observed subjects or statistical index, in order to conduct quantified research. These students are selected from the international joint business administration program in NCIST, and all are Chinese enrolled in 2008. There are 98 students totally, in which 55 were distributed into level 05 and others 04 as their initial ESL level after placement test at the very beginning of the first semester. We choose students in level 05 ( 2 classes) to be researched, after sifted, 20 of them are dropped out or not always in the same class and group, so finally we get 35 students in the same stream of ESL process from level 05 to 07,14 of them from class \#2 and 21 from class \#3, actually the former 14 from 3 groups with the distribution of 5, 5 and 4; and 21 from 4 groups with the distribution of 6, 5, 5 and 5. So the sample space is 35 students and 7 groups.

4.2 Average value and General Tendency

Now we have ESL marks in 3 levels of 35 students of 7 groups in 2 classes, as the original foundation of statistical analysis, in which grades of 5 students in Group A are shown in Table 1.

Table 1: Original Grades in Group A

\begin{tabular}{|c|c|c|c|c|c|c|c|c|c|c|c|}
\hline Class \# & Group & Name & RV05 & LS05 & GW05 & RV06 & LS06 & GW06 & RV07 & LS07 & GW07 \\
\hline 2 & A & Jiang Z. & 81 & 90 & 78 & 78 & 72 & 80 & 71 & 84 & 80 \\
\hline 2 & A & Wang L. & 94 & 100 & 79 & 84 & 85 & 78 & 81 & 77 & 70 \\
\hline 2 & A & Yang $\mathrm{T}$. & 89 & 93 & 86 & 77 & 81 & 80 & 79 & 87 & 75 \\
\hline 2 & A & Tang Y. & 86 & 100 & 84 & 78 & 90 & 75 & 78 & 79 & 70 \\
\hline 2 & A & Sun L. & 88 & 91 & 85 & 72 & 87 & 77 & 80 & 83 & 75 \\
\hline
\end{tabular}

However, the marks in different levels cannot be used and compared directly, because the difficulties of each level are not the same, which can offset the students' efforts and improvement. Therefore, the coefficient of difficulty is introduced. According to the inquiry from 10 ESL instructors in NCIST, we suppose the coefficient s are 0.9, 1.0 and 1.1, respectively for level 05, 06 and 07, which mean if level 06 is treated as base point, level 05 is $10 \%$ less difficult than 06 , conversely level 07 10\% more. So we adjust the original data with multiplying the coefficients, i.e., all the data of level 05 multiplying 0.9 , level 06 keeping stable, and level 07 multiplying 1.1. The results or adjusted data are shown in Table 2.

Table 2: Grades after Multiplying Coefficients of Difficulty

\begin{tabular}{llllllllllll}
\hline Class \# & Group & Name & RV05 & LS05 & GW05 & RV06 & LS06 & GW06 & RV07 & LS07 GW07 \\
\hline 2 & A & Jiang Z. & 73 & 81 & 70 & 78 & 72 & 80 & 78 & 92 & 88 \\
2 & A & Wang L. & 85 & 90 & 71 & 84 & 85 & 78 & 89 & 85 & 77 \\
2 & A & Yang T. & 80 & 84 & 77 & 77 & 81 & 80 & 87 & 96 & 83 \\
2 & A & Tang Y. & 77 & 90 & 76 & 78 & 90 & 75 & 86 & 87 & 77 \\
2 & A & Sun L. & 79 & 82 & 77 & 72 & 87 & 77 & 88 & 91 & 82 \\
\hline
\end{tabular}

Now we have got new data to be further analyzed. First of all, students' average marks of each ESL level can be counted on the basis of LS, GW and RV marks, shown in the Table 3. Majority of the students have made improvement in ESL learning under group dynamics. For instance, Jiang Z. in Group A gets the increasing scores of 75, 77 and 86 for each level. 
Table 3: Average Grades and Standard Deviations of Group A

\begin{tabular}{llllll}
\hline Class \# & Group & Name & ESL05 & ESL06 & ESL07 \\
\hline 2 & A & Jiang Z. & 75 & 77 & 86 \\
2 & A & Wang L. & 82 & 82 & 84 \\
2 & A & Yang T. & 80 & 79 & 88 \\
2 & A & Tang Y. & 81 & 81 & 83 \\
2 & A & Sun L. & 79 & 79 & 87 \\
\hline 2 & A & Average & 79 & 80 & 86 \\
2 & A & SD & 2.74 & 2.00 & 2.12 \\
\hline
\end{tabular}

Then we can go to Fig. 1 which shows the tendency of each group's average scores is increasing, similar to individual students. So we can say that the performance of individuals and groups are enhanced through group dynamics and group learning. For instance, the average scores of Group A are 79, 80 and 86 for each level, showing an increasing trend.

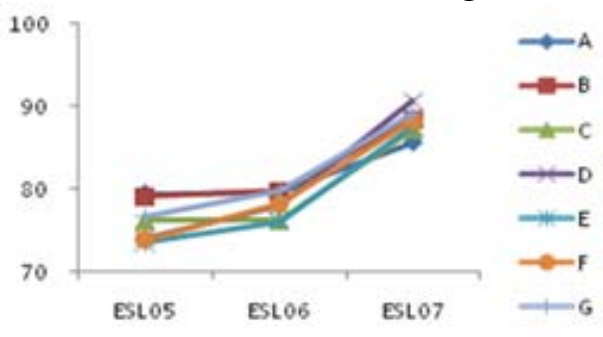

Fig. 1 Average Grade of Each Group

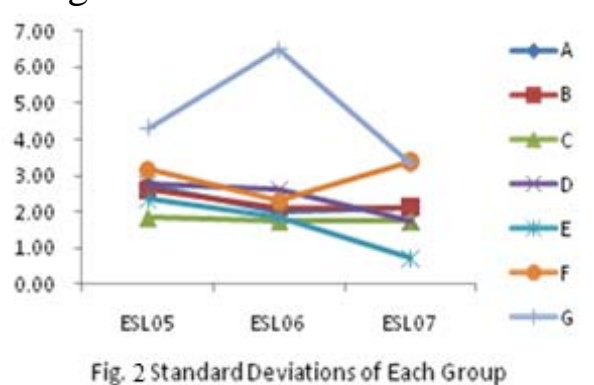

Fig. 2 Standard Deviations of Each Group

\subsection{Standard Deviation and General Tendency}

Next we shall discuss whether the changing rule of scores within a group is divergent or convergent, so we introduce the standard deviation to measure this attribution of group data. We should use the formula as $\mathrm{SD}=\sqrt{\sum\left(\mathrm{x}_{\mathrm{i}}-\overline{\mathrm{x}}\right)^{2} /(\mathrm{n}-1)}$. Now we can count the SD values of each ESL level for the 7 groups and draw a line graph as Fig.2. We discover that majority of the groups show the convergent tendency in general, i.e. the performance and scores of students within a group become close to each other, attribute to being influenced by each other under the effect of group dynamics. For example, the standard deviations of Group A are 2.74, 2.00 and 2.12, showing the gaps among the group members grow close.

\section{Conclusions}

1) Key difficulties for a student to learn English well are maintaining the interest continuously, as well as overcoming boredom and bad environment caused by individual learning. 2) As a kind of significant tool for ESL teaching and learning, group dynamics can make a benign field, space or environment to influence and revise members' psychology and behavior positively to eventually improve the English level individually and totally. 3) Driven by group dynamics, members and groups' average English level and performance are enhanced. 4) members and groups' English levels become closer, i.e., the deviations of their scores become convergent.

\section{Acknowledgement}

This work was financially supported by NCIST 131 Talent Engineering Fund. Meanwhile I appreciate Ms Shi Bo’s help for this thesis.

\section{References}

[1] Sweet, M., \& Michaelsen, L.. How Group Dynamics Research Can Inform the Theory and Practice of Postsecondary Small Group Learning. Educational Psychology Review, 2007.19(1), 31-47.

[2] Bicen, P., \& Laverie, D.. Group-Based Assessment as a Dynamic Approach to Marketing Education. Journal of Marketing Education, 2009.31(2), 96-108. 
[3] Cox, B., \& Cox, B.. Developing Interpersonal and Group Dynamics through Asynchronous Threaded Discussions: The Use of Discussion Board in Collaborative Learning. Education, 2008.128(4), 553-565.

[4] Lewin, K.. A Dynamic Theory of Personality - Selected Papers. Lewin Press, 1935

[5] Lewin, K. Frontiers in group dynamics 1. Human Relations, 1947(1), 5-41. 